\title{
Broadrange Reflectarray Element with Combined Slot and Dielectric Resonator Resonances
}

\author{
Shin-Rou LEE ${ }^{1}$, Eng-Hock LIM ${ }^{1}$, Fook-Loong LO ${ }^{1}$, Kia-Hock TAN ${ }^{2}$ \\ ${ }^{1}$ Dept. of Electrical and Electronic Engineering, Universiti Tunku Abdul Rahman, \\ Jalan Sungai Long, 43000 Bandar Sungai Long, Selangor, Malaysia \\ ${ }^{2}$ Dept. of Electronic Engineering, Universiti Tunku Abdul Rahman, \\ Kampar Campus, Jalan Universiti, Bandar Barat, 31900 Kampar, Perak, Malaysia \\ shinrou1006@gmail.com, limeh@utar.edu.my, lofl@utar.edu.my, tankh@utar.edu.my
}

Submitted June 8, 2016 /Accepted May 4, 2017

\begin{abstract}
This paper presents a dielectric resonator antenna (DRA) reflectarray unit element with multiple loading circular slots underneath in concentric form. The radii of the three slots are varied simultaneously to function as phase-shifting elements. For the case of three under-loading slots, it is very interesting to find out that the slot and $D R A$ resonances can be pulled together to provide a very broad phase range of $916^{\circ}$. Study shows that the gradient and phase range of the $S$ curve can be easily tuned by manipulating the dimensions of the under-loading slots. Waveguide method has been used to establish the simulation and measurement models. The reflection properties of the DRA unit elements loaded with different ring-shaped slots are compared, along with a complete parametric analysis. The proposed reflectarray unit element is very compact as its phase shifter can be entirely hidden beneath the DRA.
\end{abstract}

\section{Keywords}

Dielectric resonator antenna (DRA), reflectarray element, broad phase range

\section{Introduction}

Since its introduction in 1963 [1], reflectarray has attracted much attention because it is able to capture the good features of both of the reflector antenna and phased array. The emergence of microstrip-based reflectarrays [2], [3] in the late 80s has made this type of planar antennas popular for space-related applications because of their light weight, simple structure, and low cost. Despite its popularity, the antenna bandwidth of a microstrip reflectarray is usually low. It is limited by the high quality factor of the microstrip patch resonator. On top of that, the conductive loss of the metal-made microstrip can also be translated to reflection loss. This is very undesirable as it causes the radiation efficiency of the reflectarray to reduce significantly. As a result, in recent years, much attention has been diverted to the dielectric resonator antenna (DRA) because it is free from conductive loss [4]. DRA can appear in arbitrary shapes such as conical, triangular, rectangular, square, and cylindrical [5]. Various DRA reflectarrays have been explored for achieving low reflection amplitude, large reflection phase range, and slow changing rate in the $\mathrm{S}$ curve [6], [7]. However, most of the reported cases have a phase range of less than $360^{\circ}$.

Broad reflection phase range in its $\mathrm{S}$ curve is one of the most important criteria in designing a large-size reflectarray. In [8], a broadrange microstrip reflectarray that is composed of two elliptical rings has been proposed to generate a reflection phase range of $450^{\circ}$. In this case, phase shift is obtained by varying the minor axis of the elliptical rings. Despite its broad phase range, it has high reflection amplitude $(-35 \mathrm{~dB})$, which is very undesirable. In 2002, Misran et al. [9] proposed a double-layered structure which is built by stacking ring elements to provide reflection phase range of greater than $500^{\circ}$. However, the multilayer structure has made its implementation very tedious. Later, in [10], a U-shaped true time delay line was explored for designing a wideband reflectarray, where its line length is used as the phase shifter to yield a very wide phase range of $1600^{\circ}$. The reflection amplitude of this reflectarray is low, but unfortunately it requires the use of multilayer technology. A simple circular ring loaded with an open-circuited stub with variable length was also studied and it was found that it was able to give a phase range of $450^{\circ}$ [11], [12]. However, it is not easy to vary the length of the stub as the impedance matching between the ring and the stub has to be done very carefully.

In this paper, the square DRA reflectarray elements loaded with one, two, and three circular concentric slots beneath are explored. It has been found that the resonances of the slot and the DRA can be simultaneously excited. By simply manipulating the slot dimensions, the proposed structure is able to provide a reflection phase range of more than $1000^{\circ}$. This is the first-ever reported DRA reflectarray unit element which is able to provide such a broad phase range, to the authors' best knowledge. The loading effects 
of the slots will be studied. Simulation was done using the CST Microwave Studio software and measurements were conducted on a Vector Network Analyzer (VNA). Good agreement is found between the simulated and measured results.

\section{Reflectarray Unit Cell Configuration}

Figure 1(a) illustrates the perspective view of the proposed DRA reflectarray unit element with three underloading circular slots, which are aligned concentrically and made to have equal slot width $\left(W_{1}=W_{2}=W_{3}=0.50 \mathrm{~mm}\right)$. Referring to Fig. 1(b), the three circular slots are evenly placed apart $\left(G_{1}=G_{2}=0.5 \mathrm{~mm}\right)$ and etched on the top copper surface of a Duroid RO4003C substrate, which has a dielectric constant of $\varepsilon_{\mathrm{r}}=3.38$ and a thickness of $h=$ $1.524 \mathrm{~mm}$, with its reverse side laminated with another thin copper layer. A square DRA $\left(L_{\mathrm{D}}=14 \mathrm{~mm}, H_{\mathrm{D}}=6 \mathrm{~mm}\right.$, and dielectric constant of $\varepsilon_{\mathrm{r}}=7$ ) is then stacked right on top of the circular slots with the center point of its bottom surface coinciding with that of the ring-shaped slots. The radii of three slots function as the phase-shifting elements. The radii of the middle $\left(R_{2}\right)$ and outer $\left(R_{3}\right)$ ring-shaped slots are made such that $R_{2}=R_{1}+G_{1}+W_{2}$ and $R_{3}=R_{1}+G_{1}+W_{2}+$ $G_{2}+W_{3}$. This makes the circumferences of the middle and outer slots vary with the inner one $\left(R_{1}\right)$. In other words, all the ring-shaped slots can be scaled at the same time when $R_{1}$ is varied. Figure 1(c) shows a photograph of the fabricated prototype. The proposed reflectarray element is characterized using the waveguide method operating in $\mathrm{C}$ band covering the frequency range $5.85 \mathrm{GHz}-8.2 \mathrm{GHz}$. Figure 2(a) shows the simulation model. A section of waveguide $(a=34.85 \mathrm{~mm} \times b=15.8 \mathrm{~mm})$ with length of $154 \mathrm{~mm}$ has been deployed. With reference to Fig. 2(a), the unit element is placed at one end of the waveguide and electromagnetic wave is generated at the wave port. The lateral walls of the waveguide are set to be perfect electric conductor (PEC) in the simulation model. During measurement, an SMA-to-waveguide adaptor is used to connect the waveguide section to a microwave source. Also, the reference plane is de-embedded to the flange of the adaptor by using a flat shorting plate. The substrate is carefully tailored and trimmed so that it is able to fit into a rectangular trench with a depth of $\sim 1.5 \mathrm{~mm}$, as depicted in Fig. 2(b).

\section{Results and Discussion}

First, the reflection characteristics of the square DRA with three under-loading circular slots are studied for the slot dimensions of $G_{1}=G_{2}=0.5 \mathrm{~mm}$ and $W_{1}=W_{2}=W_{3}=$ $0.5 \mathrm{~mm}$. Figure 3 shows the simulated and measured reflection coefficients and reflection phases of the DRA reflectarray unit element with three under-loading slots. Referring to the figure, reasonable agreement is observed between the simulated and measured results across the frequency range of $7.3 \mathrm{GHz}-7.7 \mathrm{GHz}$, with a maximum discrepancy of $0.2 \mathrm{~dB}$. The maximum amplitude reads $\sim-0.7 \mathrm{~dB}$ at $7.36 \mathrm{GHz}$. This proves that the proposed DRA reflectarray element has only very little loss in this frequency range.

Next, the phase shifting effect of the unit element is studied by varying the radii of three circular slots $R_{1}, R_{2}$ and $R_{3}$ simultaneously. As the values for $R_{2}$ and $R_{3}$ depend on $R_{1}$, therefore it is only necessary to vary $R_{1}$ in this case. Figure 4 depicts the simulated and measured reflection amplitudes and $\mathrm{S}$ curve of the unit element at the frequency

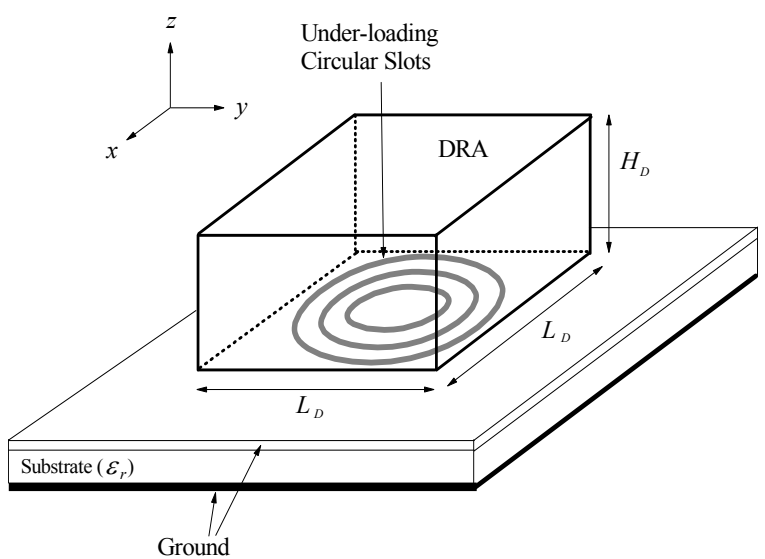

(a)

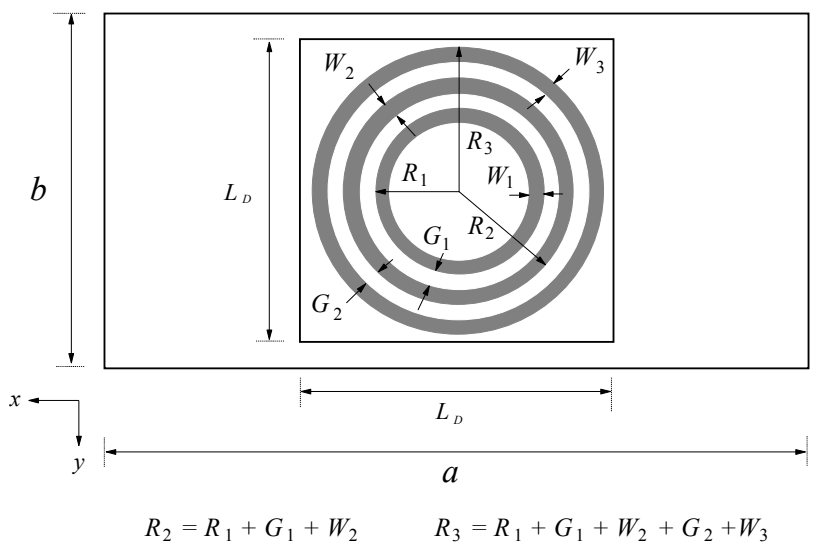

(b)

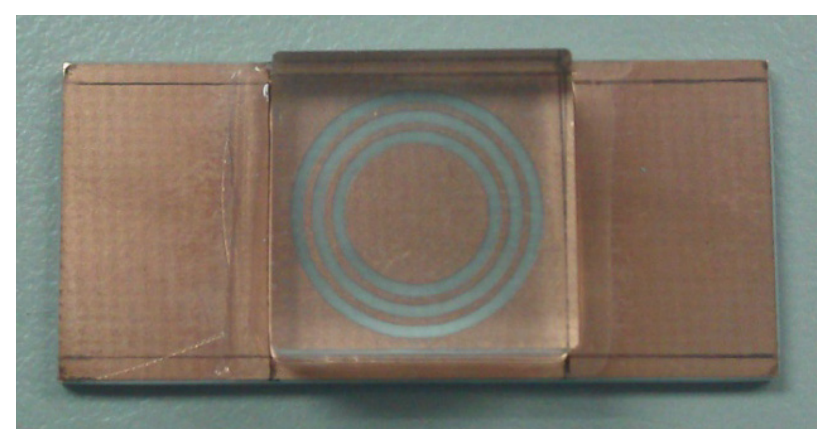

(c)

Fig. 1. Square DRA unit element loaded with 3 concentric circular slots underneath. (a) Perspective view. (b) Top-down view. (c) Photograph of the fabricated prototype. 


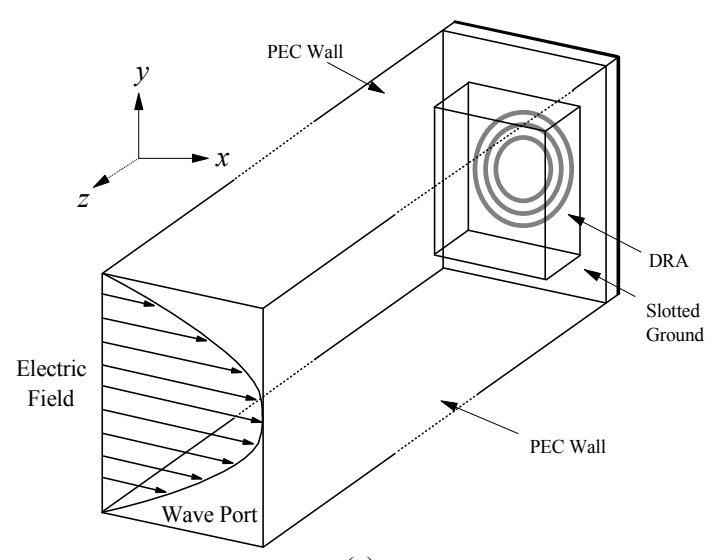

(a)

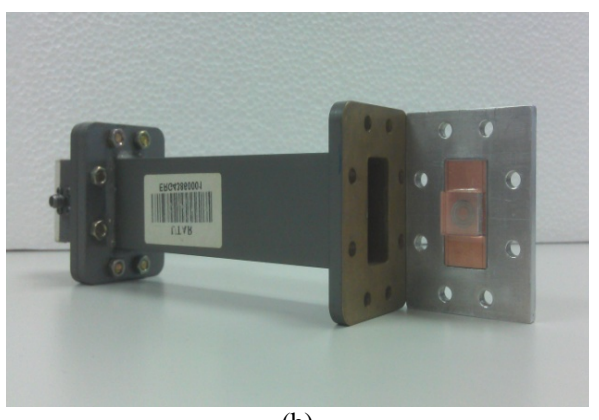

(b)

Fig. 2. (a) DRA unit element simulation model.

(b) Experimental setup for the waveguide method.

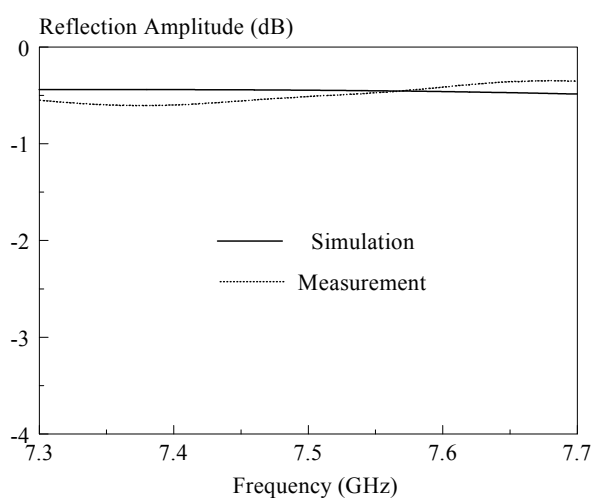

(a)

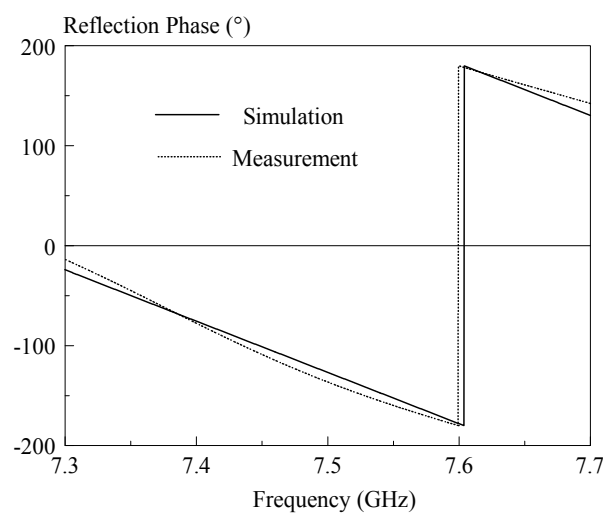

(b)

Fig. 3. Simulated and measured (a) reflection amplitudes; (b) reflection phases of the proposed DRA reflectarray unit element loaded with three circular slots $\left(G_{1}=G_{2}=\right.$ $0.5 \mathrm{~mm}$ and $W_{1}=W_{2}=W_{3}=0.5 \mathrm{~mm}$ ) beneath.

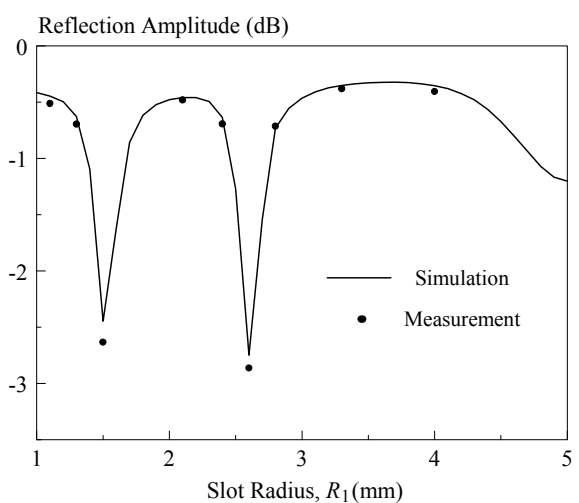

(a)

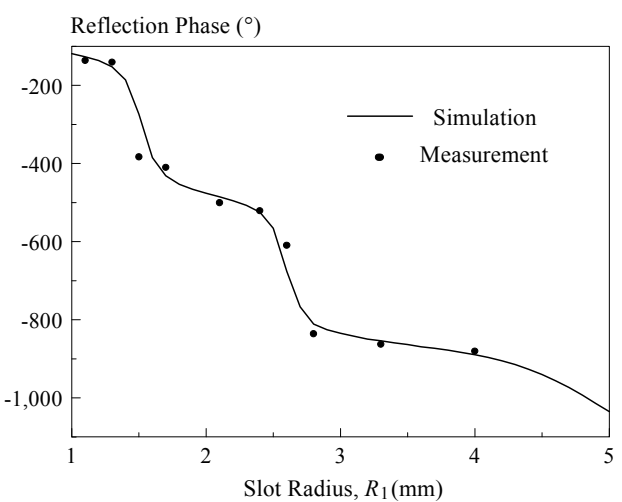

(b)

Fig. 4. Simulated and measured (a) reflection amplitudes, (b) $\mathrm{S}$ curves at $7.5 \mathrm{GHz}$ for the proposed DRA unit element with three under-loading circular slots.

\begin{tabular}{|c|c|c|c|}
\hline $\begin{array}{c}\text { Reference } \\
\text { No. }\end{array}$ & Structure & $\begin{array}{c}\text { Operating } \\
\text { Frequency }\end{array}$ & $\begin{array}{c}\text { Reflection } \\
\text { Phase Range }\end{array}$ \\
\hline Our design & $\begin{array}{c}\text { Dielectric resonator } \\
\text { antenna (DRA) with } \\
\text { three under-loading } \\
\text { circular slots }\end{array}$ & $7.5 \mathrm{GHz}$ & $916^{\circ}$ \\
\hline$[6]$ & Two rectangular DRAs & $12 \mathrm{GHz}$ & $360^{\circ}$ \\
\hline$[7]$ & $\begin{array}{c}\text { Rectangular DRA with } \\
\text { perforated ground plane } \\
\text { and rectangular concave } \\
\text { dip }\end{array}$ & $12 \mathrm{GHz}$ & $360^{\circ}$ \\
\hline$[8]$ & $\begin{array}{c}\text { Single layer microstrip } \\
\text { with double elliptical } \\
\text { rings }\end{array}$ & $11.5 \mathrm{GHz}$ & $\sim 450^{\circ}$ \\
\hline$[10]$ & $\begin{array}{c}\text { Multilayer structure with } \\
\text { the use of U-shaped true- } \\
\text { time delay line }\end{array}$ & $9.4-9.9 \mathrm{GHz}$ & $1600^{\circ}$ \\
\hline$[12]$ & $\begin{array}{c}\text { Circular ring with open- } \\
\text { circuited stub }\end{array}$ & $11.5 \mathrm{GHz}$ & $410^{\circ}$ \\
\hline
\end{tabular}

Tab. 1. Comparison of different unit elements.

of $7.5 \mathrm{GHz}$. Reasonable agreement is observed between simulation and measurement. With reference to Fig. 4(a), the reflection amplitude maximizes at slot radius of $R_{1}=$ $1.5 \mathrm{~mm}$ and $2.6 \mathrm{~mm}$, implying that the DRA reflectarray element has resonances of close to $7.5 \mathrm{GHz}$ at these two slot dimensions. The measured reflection amplitude at the two resonances are $-2.45 \mathrm{~dB}$ (simulation: $-2.63 \mathrm{~dB}$ ) and $-2.75 \mathrm{~dB}$ (simulation: $-2.86 \mathrm{~dB}$ ), respectively. Figure 4(b) depicts the measured and simulated $\mathrm{S}$ curves at different 
$R_{1}$. As can be seen from the figure, there is good agreement between the two, and a reflection phase range of $916^{\circ}$ is obtainable, which is much larger than that in [13] loaded with multiple straight slots. Table 1 compares the proposed broadrange reflectarray element with some of the relevant published structures. It is obvious that our design is able to achieve a reflection phase range much larger than those in [6], [7], [8] and [12]. Although its phase range is still lesser than that in [10], the proposed reflectarray design is much simpler and easier to fabricate as it does not involve multilayer technology.

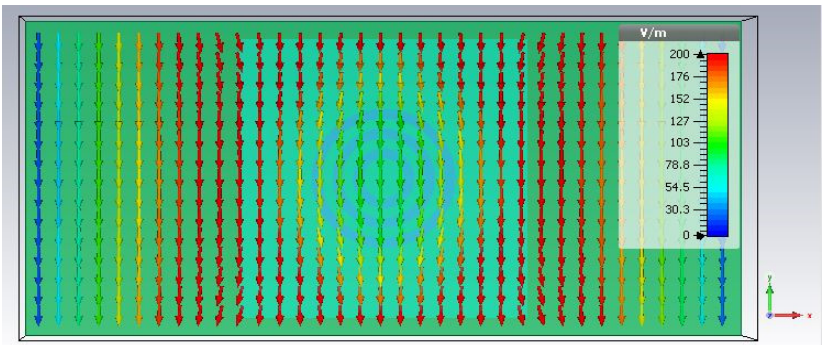

(a)

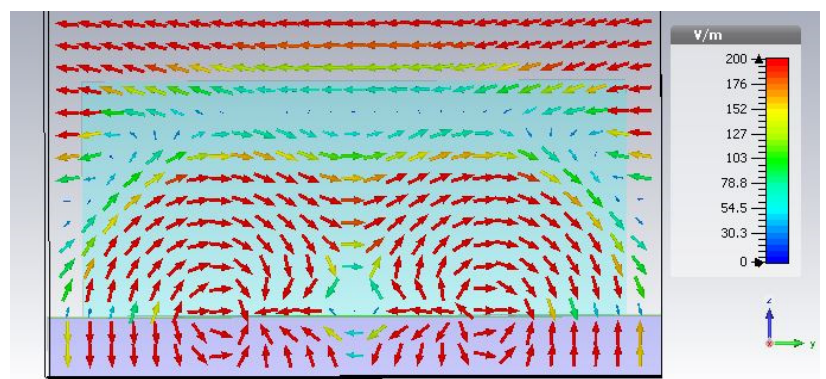

(b)

Fig. 5. Electric field distribution of the DRA reflectarray unit element for $R_{1}=1.5 \mathrm{~mm}$ at $7.5 \mathrm{GHz}$. (a) Top-down view. (b) Side view.

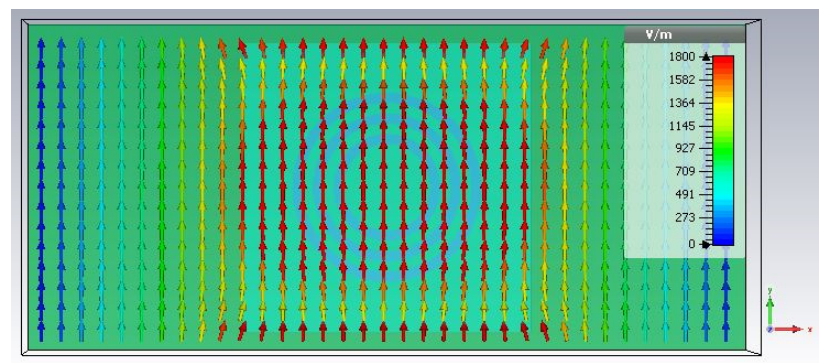

(a)

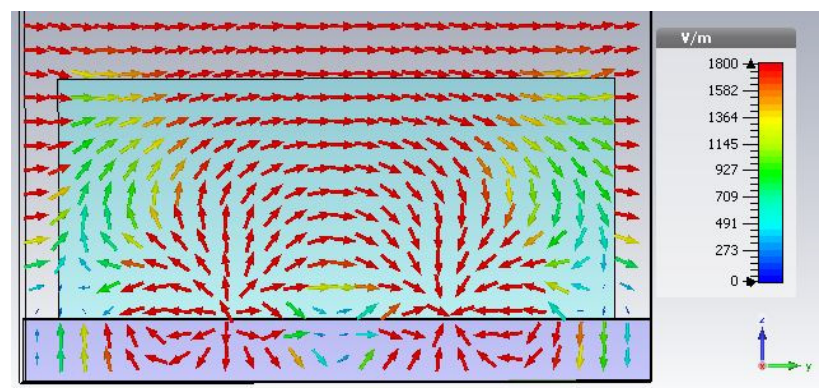

(b)

Fig. 6. Electric field distribution of the DRA reflectarray unit element for $R_{1}=2.6 \mathrm{~mm}$ at $7.5 \mathrm{GHz}$. (a) Top-down view. (b) Side view.

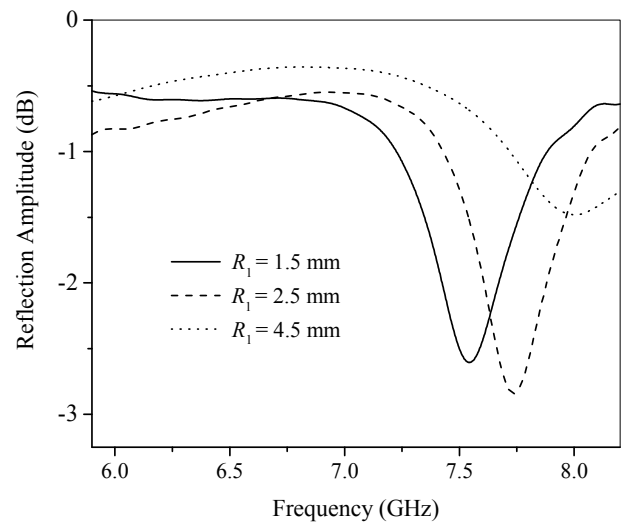

Fig. 7. The effect of radii $R_{1}$ of the three under-loading slots on the $\mathrm{TE}_{111}^{\mathrm{z}}$ mode of the DRA reflectarray unit element.

The electric field distributions for the cases $R_{1}=$ $1.5 \mathrm{~mm}$ and $2.6 \mathrm{~mm}$ are shown in Fig. 5 and 6 , respectively, at the operating frequency of $7.5 \mathrm{GHz}$. Figure 5 shows that the incident wave has caused the dielectricloaded triple slots to resonate. This resonance introduces the lower phase range for the $\mathrm{S}$ curve. By judging from the electric field patterns in Fig. 6, it can be concluded that this is the dominant $\mathrm{TE}_{111}^{\mathrm{z}}$ mode of the square DRA loaded with the three ring-shaped slots underneath. This has significantly expanded the phase range of the $\mathrm{S}$ curve, making it very broad. In brief, for the proposed element to operate properly, the DRA and the circular slots have to be positioned in the manner shown in Fig. 1 so that the varying slots $R_{1}$ can effectively excite the DRA. With the combination of the slot and DRA resonances, the proposed element is able to provide a broad phase range. The effect of the radii $R_{1}$ of under-loading slots on the $\mathrm{TE}^{\mathrm{z}}{ }_{111}$ mode of the DRA reflectarray unit element is studied by further changing $R_{1}$ to $2.5 \mathrm{~mm}$ and $4.5 \mathrm{~mm}$. It is observed that the resonance frequency of the DRA has shifted higher when the radii of the three under-loading slots is varied from $R_{1}=1.5 \mathrm{~mm}$ to $4.5 \mathrm{~mm}$, as depicted in Fig. 7 .

Parametric analysis has been performed to study the effects of the under-loading circular slots on the reflection amplitude and S curve. First of all, the gap separations between the circular slots are studied. In the first study, separation gaps between the circular slots are all varied at the same time. With reference to Fig. 8(a), reflection amplitude increases as the gaps become smaller. For the case of $G_{1}=G_{2}=0.5 \mathrm{~mm}$, as can be seen in Fig. 8(b), it is noted that the DRA unit element has two dimensions that have close resonance frequencies to the incident wave $7.5 \mathrm{GHz}$, making it able to provide very large reflection phase range. Enlarging the gap separations $\left(G_{1}, G_{2}>0.5 \mathrm{~mm}\right)$ does not help broaden the phase range as less tuning range is available in $R_{1}$ due to the limitation posed by the top-loading DRA. In the second study, with reference to Fig. 9, only one gap is changed while another one is kept unchanged $\left(G_{2}=0.2 \mathrm{~mm}\right)$. It can be observed from Fig. 9(a) that varying gap separation $G_{1}$ from $0.4 \mathrm{~mm}$ to $0.8 \mathrm{~mm}$ has effect on the reflection amplitude of the slot resonance, but less on the DRA resonance. Figure 9(b) shows that the chang- 
ing rate of the reflection phase differs when $G_{1}$ is varied. The phase range, however, is kept almost unchanged.

Next, the effect of changing the widths of the three circular slots is scrutinized. First, the widths of the three slots are varied simultaneously. As can be seen from Fig. 10(a), when the slot radius $R_{1}$ is set to be $1.8 \mathrm{~mm}$, the reflection amplitude of the slot resonance peaks at $-2.9 \mathrm{~dB}$ for the case $W_{1}=W_{2}=W_{3}=0.2 \mathrm{~mm}$. Also, the slot widths are found to affect the slot mode significantly but not too much the DRA mode. Therefore, it can be used for controlling the changing rate of the lower phase range of the $S$ curve without affecting the higher portion (DRA mode), as can be clearly seen in Fig. 10(b). With reference to the same figure, it can be concluded that narrow slots are good for lowering down the gradient of the $\mathrm{S}$ curve which is introduced by the slot mode.

For the case of changing only one slot $W_{1}$ while keeping another two unchanged $\left(W_{2}=W_{3}=0.5 \mathrm{~mm}\right)$, the reflection characteristics are studied in Fig. 11. Obviously, a change in only one slot width does not affect the reflection performance much for $R_{1}$ of less than $3.25 \mathrm{~mm}$. With reference to Fig. 11(b), the phase range can be even expanded beyond $R_{1}=3.25 \mathrm{~mm}$ when $W_{1}$ is made narrower. But in this case, $R_{1}$ cannot be stretched so far as this parameter is limited by the footprint of the DRA. To further understand the slot effect, the width of the middle slot is

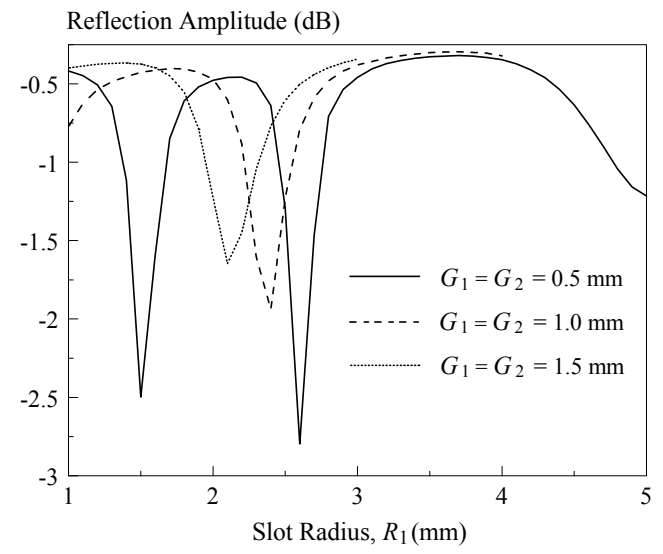

(a)

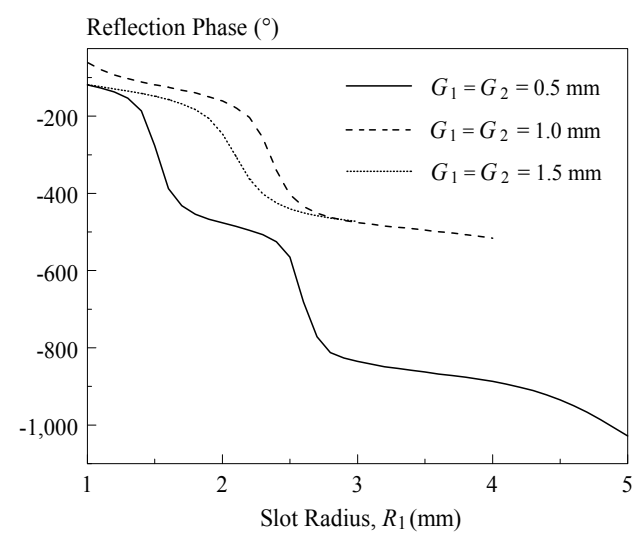

(b)

Fig. 8. Effect of the gap separation on (a) reflection amplitude; (b) S curve.

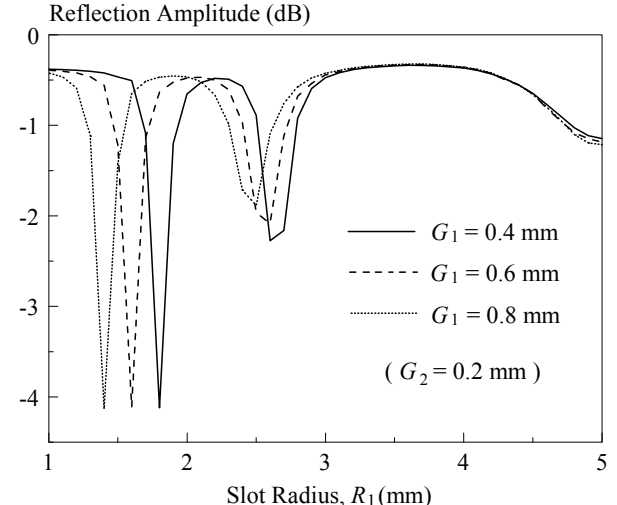

(a)

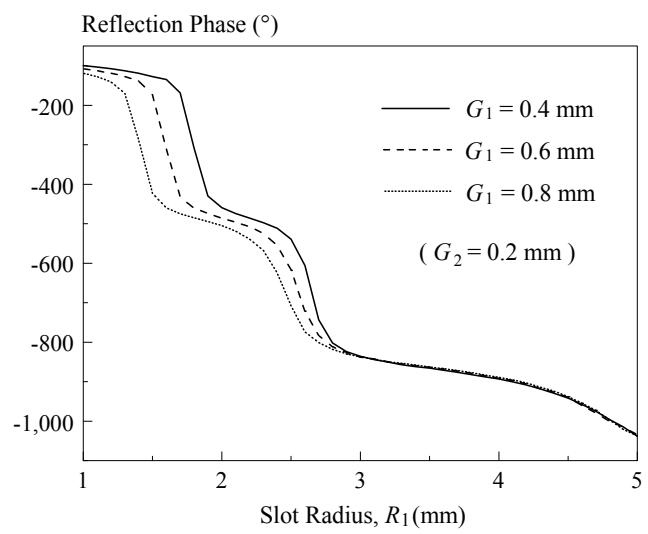

(b)

Fig. 9. Effect of changing the gap separation $G_{1}$ (with $G_{2}=$ $0.2 \mathrm{~mm}$ ) on the (a) reflection amplitude; (b) $\mathrm{S}$ curve.

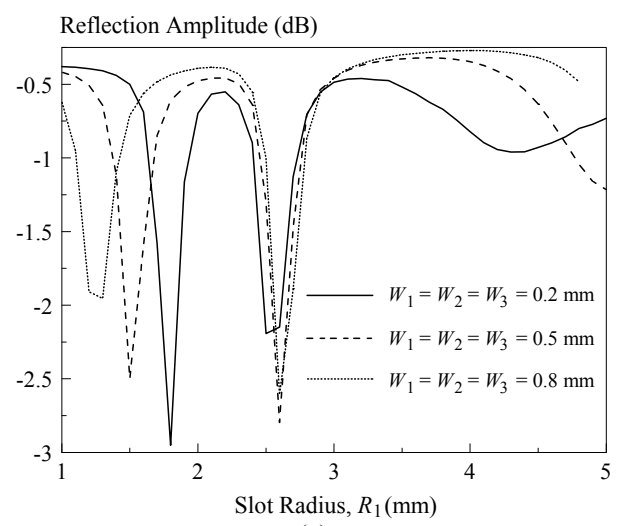

(a)

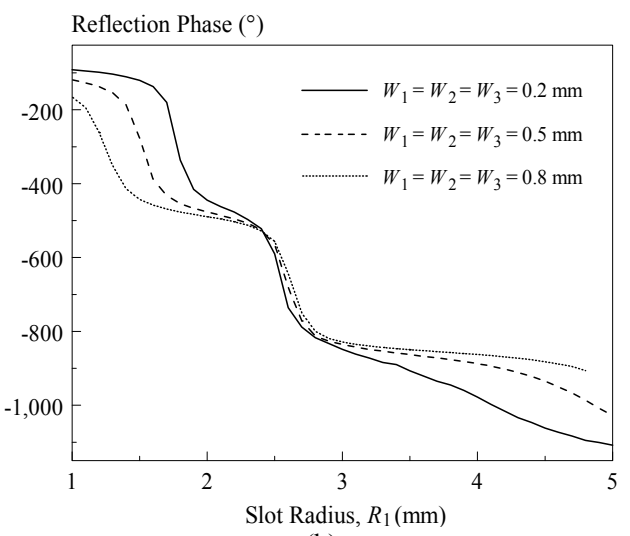

(b)

Fig. 10. Effect of changing slot widths $W_{1}, W_{2}, W_{3}$ of the 3 circular slots on the (a) reflection amplitude; (b) $\mathrm{S}$ curve. 


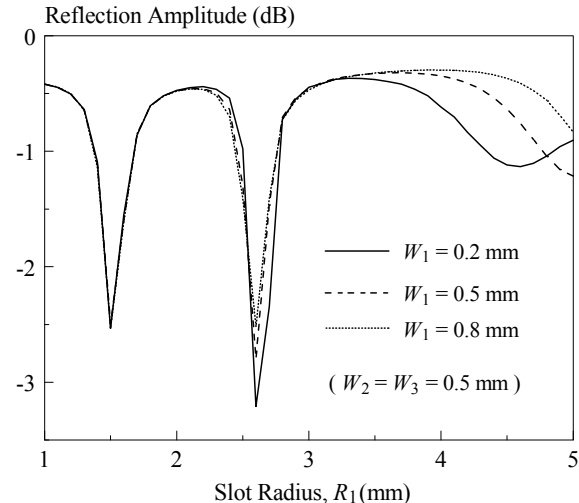

(a)

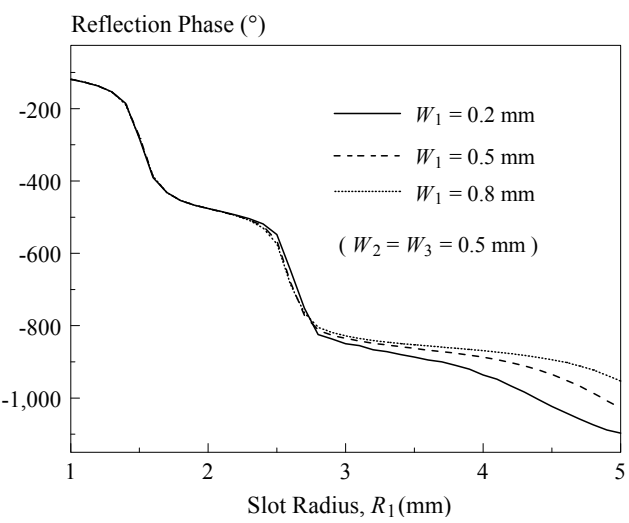

(b)

Fig. 11. Effect of changing the circular slot width $W_{1}$ on (a) the reflection amplitude; (b) S curve.

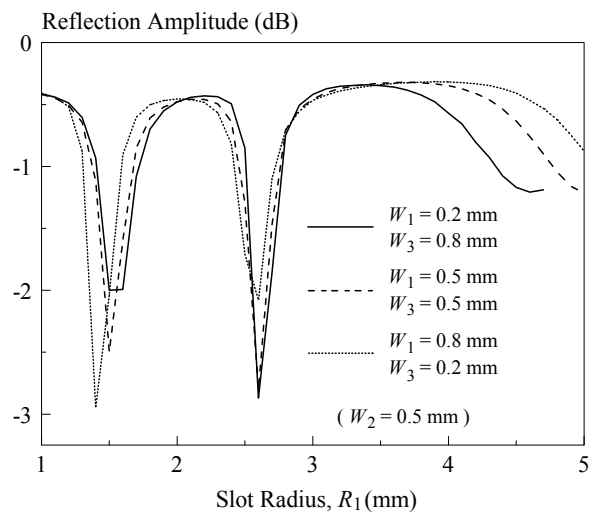

(a)

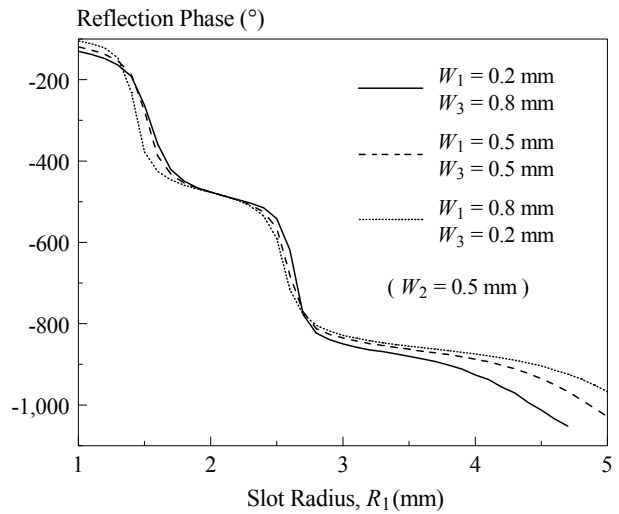

(b)

Fig. 12. Effect of changing the inner and outer slots $\left(W_{1}\right.$ and $W_{3}$ ) on the (a) reflection amplitude; (b) $\mathrm{S}$ curve.

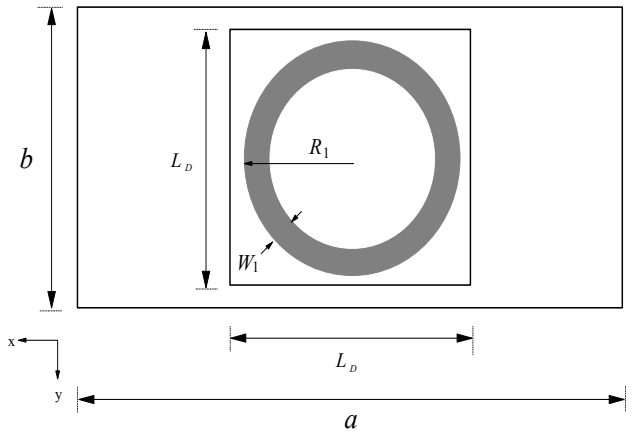

(a)

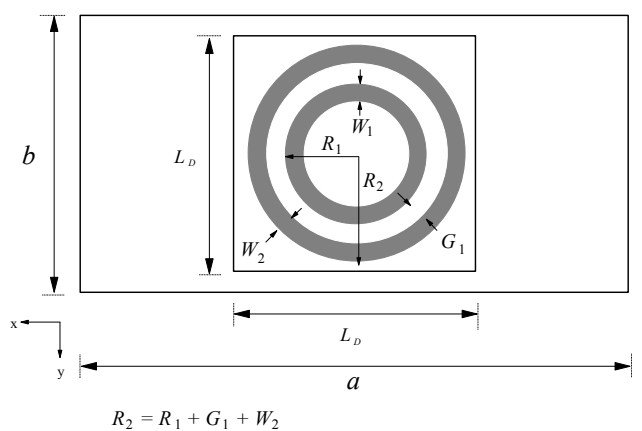

(b)

Fig. 13. (a) Square DRA reflectarray unit element loaded with (a) one circular slot and (b) two circular slots underneath.

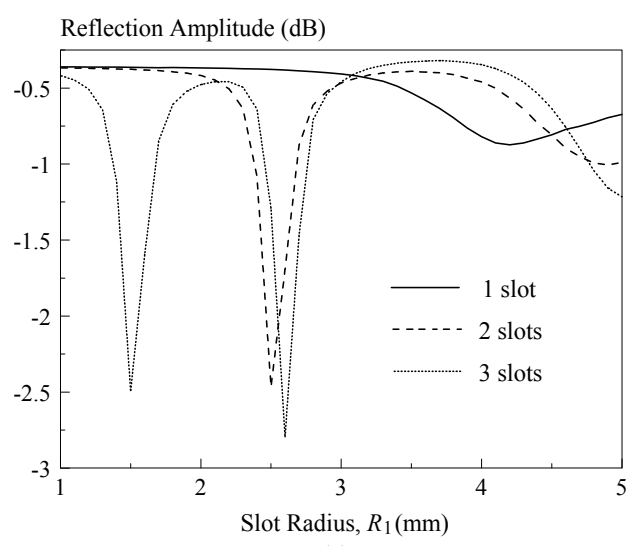

(a)

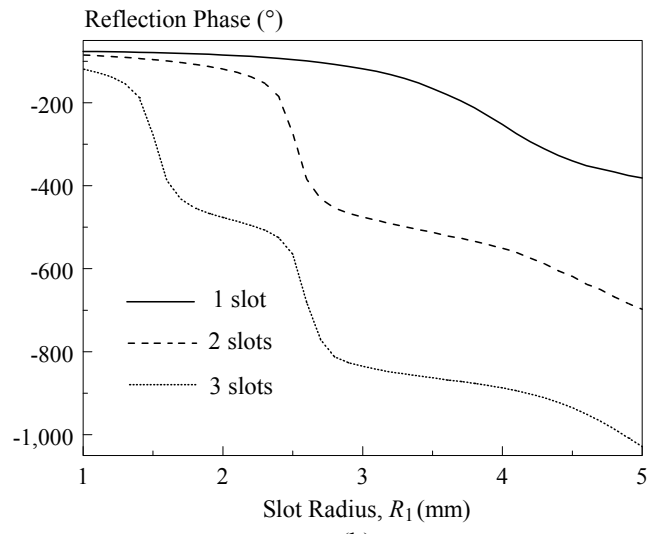

(b)

Fig. 14. Comparison of the (a) reflection amplitude, (b) S curve of the DRA reflectarray unit elements with one, two, and three under-loading slots. 
kept a constant $\left(W_{2}=0.5 \mathrm{~mm}\right)$ but the inner and outer slots $\left(W_{1}\right.$ and $\left.W_{3}\right)$ are changed at the same time. The corresponding reflection amplitude and $\mathrm{S}$ curve are studied in Fig. 12. As can be seen from Fig. 12(b), it is clear that the phase range can be expanded far beyond $R_{1}=3 \mathrm{~mm}$ by manipulating $W_{1}$ and $W_{3}$. For the case $\left(W_{1}=0.2 \mathrm{~mm}, W_{2}=\right.$ $0.5 \mathrm{~mm}, W_{3}=0.8 \mathrm{~mm}$ ), shown in Fig. 12(b), a nice $\mathrm{S}$ curve with slow gradient is obtainable with a very broad phase range of $1000^{\circ}$, which is sufficient for designing large-size reflectarrays.

Similar DRA reflectarray elements loaded with less slots underneath are also simulated for comparison. Due to footprint limitation of the DRA, in this paper, the number of under-loading slots is limited to three. The configurations of the respective unit elements are shown in Fig. 13. The slot width of the single slot case (Fig. 13(a)) is $W_{1}=$ $0.5 \mathrm{~mm}$; while the dimensions of the double slots case (Fig. 13(b)) are given by $W_{1}=W_{2}=0.5 \mathrm{~mm}, G_{1}=0.5 \mathrm{~mm}$. For the latter, the radius of the inner slot $R_{1}$ is varied and the radius of the outer is defined as $R_{2}=R_{1}+G_{1}+W_{2}$. In other words, $R_{2}$ changes as a function of $R_{1}$. Other design parameters are similar to those in Fig. 1. Again, the radii of the slots are varied simultaneously to generate phase shift in reflection. The reflection amplitudes and $\mathrm{S}$ curves for the cases of single and double slots are studied in Fig. 14. Also given are the results for the triple slots. With reference to Fig. 14(b), it is obvious that only with three underloading slots, can the slot and DRA resonances be brought together to form a broad phase range.

\section{Conclusion}

Multiple concentric circular slots are loaded underneath a square DRA for broadening the phase range of the $\mathrm{S}$ curve. It has been found that the slot resonance and the dominant resonance of the square DRA reflectarray element can be combined to achieve a broad phase range of $916^{\circ}$ in the $\mathrm{S}$ curve, which is sufficient for designing many large-size reflectarrays. Also, it was found that the phase range of the DRA reflectarray unit element can be further extended by manipulating the under-loading slots. Electric fields have been analyzed for both of the slot and DRA modes, with good agreement observed between the simulated and measured results. Since the circular slots are placed beneath the DRA, this reflectarray element does not need additional footprint, making it very compact.

\section{Acknowledgments}

The work described in this paper was supported by the Science Fund (Project No.: 06-02-11-SF0154) provided by the Ministry of Science, Technology and Innovation, Malaysia. Part of the project was also sponsored by the UTAR Research Fund 2013 (Project No.: 6200/LA5).

\section{References}

[1] BERRY, D., MALECH, R., KENNEDY, W. The reflectarray antenna. IEEE Transactions on Antennas and Propagation, 1963, vol. 11, no. 6, p. 645-651. DOI: 10.1109/TAP.1963.1138112

[2] HUANG, J., ENCINAR, J. A. Reflectarray Antenna. $1^{\text {st }}$. ed., Hoboken: John Wiley \& Sons, 2007. ISBN: 9780470084915

[3] POZAR, D. M., TARGONSKI, S. D., SYRIGOS, H. D. Design of millimeter wave microstrip reflectarrays. IEEE Transactions on Antennas and Propagation, 1997, vol. 45, no. 2, p. 287-296. DOI: $10.1109 / 8.560348$

[4] LONG, S. A., MCALliSTER, M., LIANG, S. The resonant cylindrical dielectric cavity antenna. IEEE Transactions on Antennas and Propagation, 1983, vol. 31, no. 3, p. 406-412. DOI: 10.1109/TAP.1983.1143080

[5] PETOSA, A., ITTIPIBOON, A. Dielectric resonator antennas: A historical review and the current state of the art. IEEE Antennas and Propagation Magazine, 2010, vol. 52, no. 5, p. 91-116. DOI: 10.1109/MAP.2010.5687510

[6] ABD-ELHADY, A. M., ZAINUD-DEEN, S. H., MITKEES A. A., et al. Wideband rectangular dielectric resonator elements reflectarray. In Proceedings of the Middle East Conference on Antennas and Propagation (MECAP). Cairo (Egypt), 2012, p. 1-5. DOI: 10.1109/MECAP.2012.6618208

[7] ZAINUD-DEEN, S. H., GABER, S. M., ABD-ELHADY, A. M., et al. Wideband perforated rectangular dielectric resonator antenna reflectarray. In Proceedings of the IEEE International Symposium on Antennas and Propagation (APSURSI). Spokane (Washington), 2011, p. 113-116. DOI: 10.1109/APS.2011.5996653

[8] LI, Y., BIALKOWSKI, M. E., SAYIDMARIE, K. H., et al. Singlelayer microstrip reflectarray with double elliptical ring elements for bandwidth enhancement. Microwave and Optical Technology Letters, 2011, vol. 53, no. 5, p. 1083-1087. DOI: 10.1002/mop. 25912

[9] MISRAN, N., CAHILL, R., FUSCO, V. F. Reflection phase response of microstrip stacked ring elements. Electronic Letters, 2002, vol. 38, no. 8, p. 356-357. DOI: 10.1049/el:20020257

[10] CARRASCO, E., BARBA, M., ENCINAR, J. A. Aperture-coupled reflectarray element with wide range of phase delay. Electronic Letters, 2006, vol. 42, no. 12, p. 667-668. DOI: 10.1049/el:20060472

[11] LI, Y., BIALKOWSKI, M. E., SAYIDMARIE, K. H., et al. Singlelayer reflectarray employing circular ring with open-circuited stub as phasing element. In Proceedings of the IEEE International Symposium on Antennas and Propagation (APSURSI). Spokane (Washington), 2011, p. 2168-2171. DOI: 10.1109/APS.2011.5996942

[12] LI, Y., BIALKOWSKI, M. E., ABBOSH, A. M. Single-layer reflectarray with circular rings and open-circuited stubs for wideband operation. IEEE Transactions on Antennas and Propagation, 2011, vol. 60, no. 9, p. 4183-4189. DOI: 10.1109/TAP.2012.2207060

[13] S. R. LEE, E. H. LIM, F.-L. LO. DRA reflectarray unit elements with thin under-loading parallel slots. Progress In Electromagnetics Research C, 2014, vol. 48, p. 103-110. DOI: 10.2528/PIERC14020504

\section{About the Authors...}

Shin-Rou LEE received the Bachelor of Engineering (Hons) Electronic and Communications Engineering from 
Universiti Tunku Abdul Rahman in 2014. She is currently taking a full time Master Degree (Research) at Universiti Tunku Abdul Rahman under the Dept. of Electrical and Electronic Engineering. Her main research interests are reflectarray and transmitarray antennas.

Eng-Hock LIM was born in Selangor. He received his Ph.D. from the City University of Hong Kong. His research interests include dielectric resonator antenna, reflectarray, transmitarray, and RFID design.

Fook-Loong LO was born in Kuala Lumpur. He received his Ph.D. from the University of Hong Kong. His research interests include baseband communications and signal processing.

Kia-Hock TAN was born in Ipoh. He received his Ph.D. from University of London. His research interests include oscillator design and mixer technologies. 